\title{
Study of Investment Decisions and Personal Characteristics through Risk Tolerance: Moderating Role of Investment Experience
}

$$
\begin{aligned}
& \text { رسك رو ادارى كـ ذريع سرمايـ كارى كح فيصلون اور ذاتى خصوصيات كا مطالعه: سرمايم كارى كـ } \\
& \text { تجربـح كا اعتدال بِند كردار }
\end{aligned}
$$

\begin{abstract}
Investment decisions could be affected by behavioral biases associated with personal characteristics. This study empirically investigates the effect of personal characteristics on investors' investment decision through risk tolerance. Furthermore, investment experience moderates the nexus between personal characteristics and risk tolerance. The scale consisting of 24 items was used related to selected constructs and variables. Data was collected form 175 individual investors of Pakistan Stock Exchange. PLS-SEM was used to make statistical analysis. The findings indicate that extraversion has substantial positive impact on investment decisions. Moreover, risk tolerance partially mediates the relationship between extroversion and investment decisions. The relationship between introversion and investment decisions is negative and risk tolerance partially mediates the aforesaid relationship. Furthermore, it is statistically proved that investment experience substantially moderates the association between extraversion and risk tolerance. However, investment experience does not play any conditional role in the association between introversion and risk tolerance. This study can be helpful for financial advisors to provide best consultancy to their clients (investors), while considering their personal characteristics.
\end{abstract}

Keywords: Extraversion, Introversion, Investment Experience, PLS-SEM, Risk Tolerance.

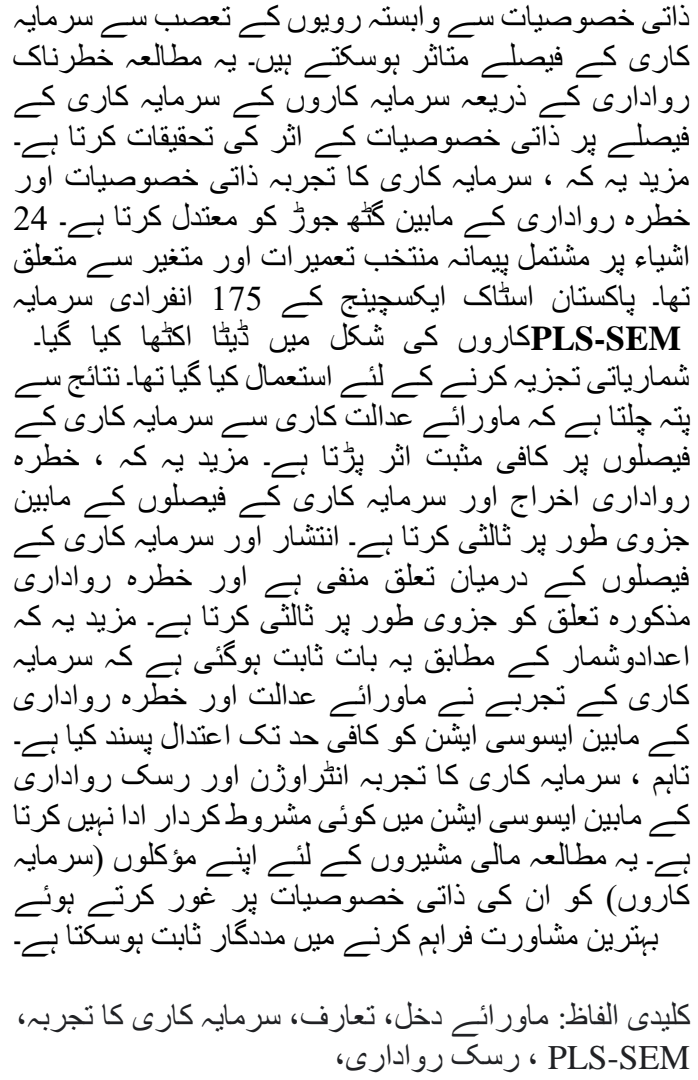

\footnotetext{
${ }^{20}$ Corresponding Author, Lecturer, Department of Management Sciences, University of Okara, Okara, Punjab, Pakistan.

${ }^{21}$ Associate Professor, Hailey College of Commerce, University of the Punjab, Lahore, Punjab, Pakistan.

${ }^{22}$ Assistant Professor, Hailey College of Commerce, University of the Punjab, Lahore, Punjab, Pakistan.

${ }^{23}$ PhD Scholar, Hailey College of Commerce, University of the Punjab, Lahore, Punjab, Pakistan.
} 


\section{Introduction}

Investment decisions by individual investors are based on publically available market information as evident by Markowitz's portfolio theory (1952) and Fama efficient market theory (1970). The underlying assumption of these traditional finance theories is that market information about investment is perfectly and readily available to all investors. Hence, all investment decisions by individual investors are rational (Sadiq \& Amna, 2019). In contrast, behavioral finance theories i.e. prospect theory and theory of cognitive dissonance challenge the rationality of investment decisions, as investors have limited market knowledge (Ricciardi \& Simon, 2000).

Consequently, investors make opportunistic investment decisions which are manipulated by psychological and personal biases (Kourtidis, Śević, and Chatzoglou, 2011).

It is argued that investors are faced with complex financial decision-making process which requires sufficient time and effort to rationally analyze different alternatives. Investors may find it more convenient to make subjective financial decisions instead of going through complicated process of systematic evaluation and selection of investment alternatives (Ibbotson, Idzorek, Kaplan, \& Xiong, 2018). Moreover, prospect theory states that subjects (investors) are always guided by their persistent biases that come from their psychological factors, thus affecting their choices (investment decisions) especially under conditions of uncertainty (Ricciardi \& Simon, 2000). Personality is one of the most important psychological biases that manipulate investment decisions. Personality word is basically originated from Latin word Persona which means the aspect of someone's character that is presented to others or perceived by others (Radin, 1932). Extroversion and introversion are two distinct personal characteristics among others (agreeableness, openness to experience and neuroticism) (Dhiman \& Raheja, 2018). On the similar note, Eysenck (1982) developed a theory of personality by using a more systematic approach. He proposed two important behavioral dimensions: extraversion and neuroticism.

Risk tolerance refers to the attitude of investors towards risks (Lippi \& Rossi, 2020). There are three main risk preferences: risk averse, risk neutral and risk taking (Lippi \& Rossi, 2020). Standard financial theory assumes human as a rational animal who exhibits risk averse behavior. However, in behavioral finance, it is assumed that these risk preferences are shaped by individual perceptions towards risk. Individual perception is influenced by personal characteristics of individual (Dhiman \& Raheja, 2018; Mishra, 2018).

The extant literature confirms that demographics factors of investors play important role while making investment decisions (Powell \& Ansic, 1997). Various demographic factors i.e. educational qualification, income, marital status, gender, age, and investment experience are relevant while studying investment decisions (Baruah \& Parikh, 2018; Chavali \& Mohanraj, 2016). Out of these factors, investment experience is most important demographic factor that influences risk tolerance, as investors learn from their previous investments and they may become more tolerant towards risk with the passage of time. In literature, investment experience has been tested as an independent variable for its influence on risk tolerance and investment decisions (Awais, Laber, Rasheed, \& Khursheed, 2016). Dearth of empirical evidence is found to gauge the aforesaid relationship. Thus, this study aims to examine the conditional role of investment experience in the relationship between personal characteristics and risk tolerance which ultimately influence investment decisions.

This paper primarily focuses on personal characteristics (extroversion and introversion) and their inter-relationship with investment decisions. Furthermore, risk tolerance is tested for its intervening role in the association between personal characteristics and investment decisions. The conditional role of investment experience was examined in the relationship between personal characteristics and investment decisions. Thus, mediated-moderation model is employed for this study. This model is tested on the individual investors of Pakistan Stock Exchange (PSX). In Pakistan, economy is not strong enough due political instability. In these circumstances, investors are more conscious for their investment decisions. Stock market fluctuations may become the prime reason for change in investment decisions by investors (Sadiq \& Amna, 2019). In accordance with deficiencies found in extant literature, this study aims to predict the impact of personal characteristics (extraversion and introversion) on investments decisions; examine the intervening role of risk tolerance in the association between personal characteristics and investment decisions, and to identify the conditional role of 


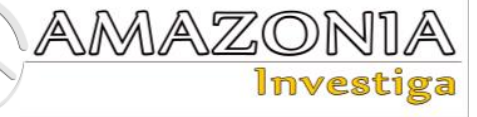

investment experience in nexus between personal characteristics and risk tolerance.

\section{Literature Review}

This section comprises of two parts. The first part of this section presents brief review of extant theories related to variables of interest which includes: Eyesenk theory of extraversion and introversion, theory of cognitive dissonance, and prospect theory. The second part of this section covers the review of empirical studies related to the variables.

\section{Theoretical Review}

Grounded theories of economics assume that human beings exhibit risk avoiding behavior in their day to day economic decisions. However, existing literature violates this basic economic assumption of risk avoiding behavior as a fundamental trait in people. Psychologists are the proponents of the concept that individual differences shape up the financial decision making in unidirectional construct (Perugini \& Raad, 2001). Behavioral finance theories supporting this concept included: Eysenek theory of personality, theory of cognitive dissonance, and prospects theory.

Eysenck (1982) adopted a more systematic approach to develop a theory of personality, as he emphasized the importance of biological factors for personality and intelligence. He argued that genetics affects a person's ability to cope with the changing environment. Eysenk (1950), through factor analysis, proposed that behaviors can be categorized into two major dimensions: Extraversion/introversión and Neuroticism/Stability. Eyesenk grouped these dimensions as second order personality traits. According to Eyesenk, Extraverts are social, excitement seeker, active and optimistic. They tend to be risk takers and love thrill, as they have inherited under aroused nervous system (Pak \& Mahmood, 2015). Investors having extroversion personality trait usually over-estimate the gains and under-estimate the loss (Pak \& Mahmood, 2015). In contrast, Introverts, having overaroused nervous system, are quite, reserved and depressed. They do extensive plan and control their emotions. Second dimension, neuroticism can be measured on the scale of emotional stability. Someone high on the neuroticism is more unstable and may quickly be worried and anxious than others (Revelle, 2016; Robinson, 1986). This theory of personality helps to justify the nexus between personal characteristics, risk tolerance and investors' investment decisions.
Festinger's theory of cognitive dissonance narrates that a person feels anxiety and internal tension when exposed to conflicting beliefs. Consequently, the individuals tend to mitigate internal conflict in any one of two ways: 1) by changing their beliefs, opinions, past values and feelings, or 2) by attempting to rationalize and justify their choices. This theory may relate to financial cognitive dissonance faced by investors or traders in the stock market. Investors are expected to behave in any of two ways: either by rationalizing their investment decisions by following personal view point, or by changing their belief of traditional finance to behavioral finance (Ricciardi \& Simon, 2000). Prospect theory, developed by Kahneman and Tversky (1979), states that psychological factors i.e., personal characteristics lead to persistent biases that influence investors' decisions in the scenario of uncertainty. Resultantly, people do not always take rational decisions. Moreover, prospect theory states that preferences are based on decision weights. Thus, preferences and perceptions vary from person to person. Similarly, stock investors assess expected profit or loss on the basis of perceptible risk and their risk preferences. Succinctly, investors decisions are influenced by their personal characteristics and risk preferences (Ricciardi \& Simon, 2000).

\section{Empirical Review}

\section{Personal Characteristics and Investment Decisions}

Investment perceptions and decision making styles are influenced by personality differences. Anxiety among people leads to risk averse behavior. Resultantly, anxious people tend to save instead of investments. On the other hand, traits like extraversion and optimistic among people lead to risk taking behavior. Thus, extroverted people tend to make risky investments. Moreover, decision making style have a mediating role in the nexus between personality traits and financial decisions (Gambetti \& Giusberti, 2019).

Czerwonka (2019) studied this relationship by using Big-Five personality model (that is considered to be the most comprehensive instrument to judge the personality type) and investment decisions. This study found that Big Five personality traits, cognition, and culture are of the huge importance while shaping up the financial behavior. Investors with high cognition tend to lower risk taking propensity. On the other end, People with high scores on extraversion and low score on introversion exhibit high risk taking 
behavior (Czerwonka, 2019). According to Oehler et al. (2018), introvert individual choose portfolio comprising of assets with minimum risk as compared to extroverted individuals. Extraverted people are ready to pay high for financial assets. In addition, extraverts prefer riskier assets having uncertain prices. Whereas, introverted people invest in those assets having less risk and certainty of fixed returns (Oehler et al., 2018). Thus, it is concluded that behavioral biases affect the risk tolerance and investment decisions (Dickason et al., 2018).

\section{Role of Risk Tolerance}

A group of researcher studied the relationship between personal characteristics and risk tolerance among investors, as mentioned in preceding section. The findings of these studies imply that psychological biases faced by the investors affect their financial risk tolerance (Kubilay \& Bayrakdaroglu, 2016). Likewise, another group of researcher studied the nexus between risk tolerance and financial decisions by individual investors ( Baruah \& Parikh, 2018; Aini \& Lutfi, 2019).

Moreover, some researchers studied the relationship between personality traits and investment decisions through risk tolerance and found that personality traits have significant influence on investment decisions through financial risk tolerance behavior ( Akhtar et al., 2018; Kanagasabai \& Aggarwal, 2020; Perugini $\&$ Raad, 2001). The intervening role of risk tolerance is also confirmed by the study of Pak and Mahmood (2015) who found that personality traits significantly influence various investment decisions (like purchase of assets and financial securities) through risk tolerance. Similarly, the study conducted by Sadiq and Amna (2019) found that risk tolerance partially mediates the nexus between personality traits and investment decisions. Based of extant literature, this study aims to investigate the intervening role of risk tolerance in the nexus between personality traits and investment decisions.

\section{Role of Investment Experience}

Various extant studies found that the relationship between personality traits and financial performance can by moderated by several factors such as gender, age, financial literacy, and investment awareness. Social influence can outline this relationship during financial decision-making process (Akhtar et al., 2018). Demographics, especially gender, are of greater importance for assessing differences in financial risk behavior (Chavali \& Mohanraj, 2016). It has been proved that males are more risk tolerant in comparison to females (Czerwonka, 2019). Laboratory experiments have also proved that men show more risk seeking behavior as compared to women irrespective of cost, ambiguity and information (Powell \& Ansic, 1997). Similarly, age effect has been found for having a significant impact on risk tolerance behavior (Yao et al., 2011). In addition to gender and age, financial literacy and investment awareness have significant impact on stock market participation (Aren \& Zengin, 2016). Financial education programs can be used to enhance financial understanding of individual investors (Mishra, 2018; Sadiq \& Amna, 2019).

Ahmad et al. (2016) concluded that financial literacy and demographics have been proved as an important antecedent for financial decision making. Personality traits seem to be unchanged over the life of the individual and its importance for shaping up financial behavior is clearly evident from the literature. Extant literature confirms that most of the demographic variables have been tested as antecedent for risk tolerance and investment decisions. Among these factors, investment experience has also found an important antecedent to risk tolerance as Awais et al. (2016) found that higher investment experience leads to greater risk tolerance. Thus to fill this gap, there is pressing need to investigate the conditional role of investment experience in the relationship between personality traits and investment decisions.

\section{Conceptual Framework}



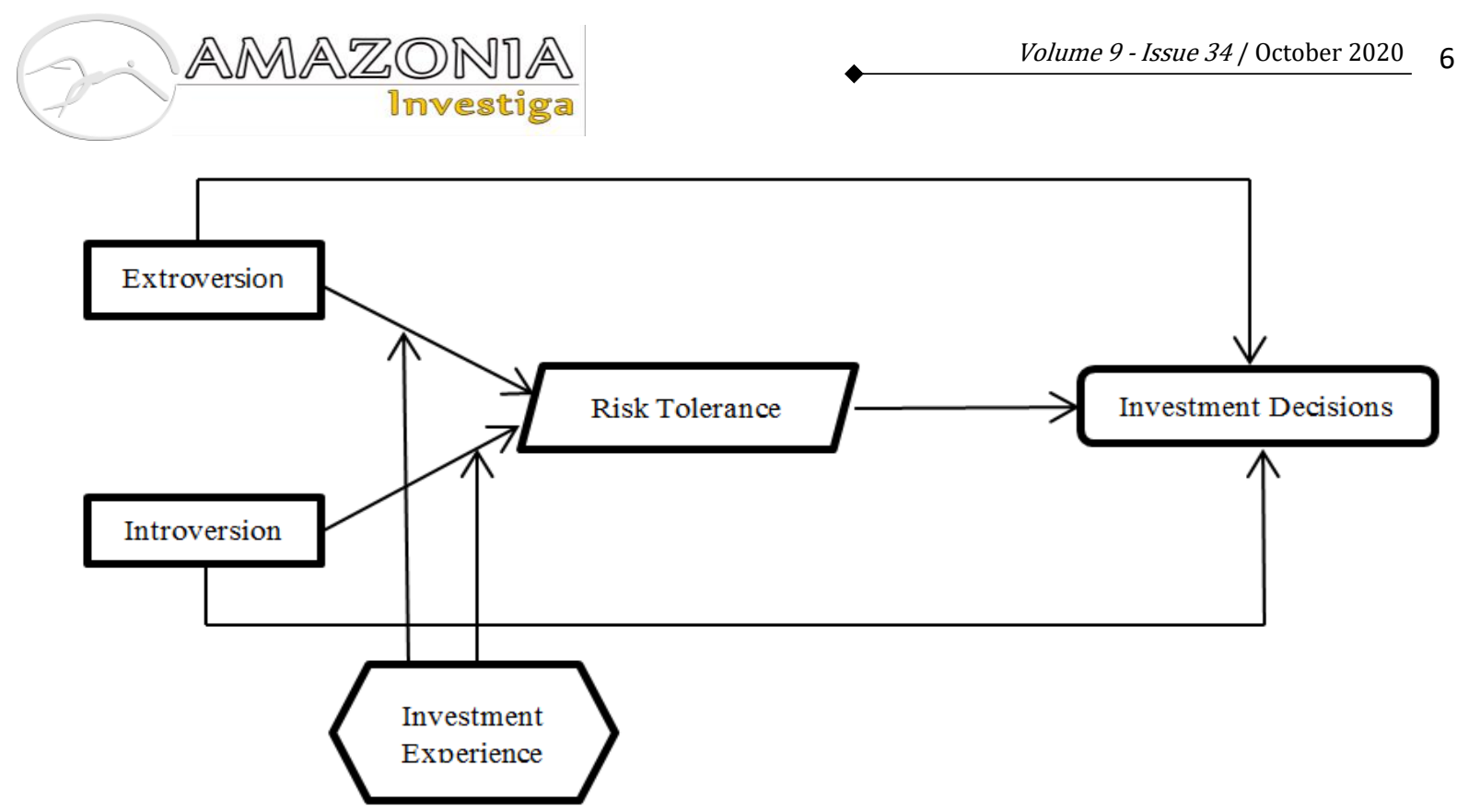

Figure I. Conceptual Framework.

\section{Hypotheses Development}

Due to inconsistencies and theoretical conflict observed in extant literature, proposed null hypotheses to testify the nexus among the variables under consideration.

$H_{0_{1}}$ : Extraversion has no impact on investment decisions made by individual investors.

$\mathrm{H}_{\mathrm{o}_{2}}$ : Introversion has no impact on investment decisions made by individual investors.

$H_{0_{3}}$ : Risk tolerance does not mediate the association between extraversion and investment decisions.

$H_{\circ}$ : Risk tolerance does not mediate the association between introversion and investment decisions.

$H_{0_{5}}$ : Investment experience does not moderate the mediating role of risk tolerance in the association between extraversion and investment decisions.

$H_{0_{5}}$ : Investment experience does not moderate the mediating role of risk tolerance in the association between introversion and investment decisions.

\section{Methodology}

The population of his study was stock investors who have experience of investment at Pakistan Stock Exchange (PSX). Convenience sampling method was employed and faced difficulties in accessing investors due to COVID-19. The use of convenience sampling in in accordance with extant literature (Liaqat, Mahmood, \& Ali, 2020; Mehtab, 2019; Salman, Khan \& Javed, 2020). Researchers distributed 200 self-administered questionnaires among individual investors. After excluding incomplete responses, 175 were found appropriate for statistical analysis.

\section{Instrument Development}

The questionnaire was adapted after extensive review of literature. The survey instrument was comprised of two sections. The first section is about demographic information which include information about age and investment experience of individual investors. The second part is about personal characteristics, risk tolerance, and investment decisions of investors by using 5point Likert scale (ranging from Strongly Disagree to Strongly Agree) to measure the variables of interest.

\section{Operationalization of Variables}


Table 1.

Measurement Scale.

\begin{tabular}{llll}
\hline Variables & Operational definition & $\begin{array}{l}\text { Number of } \\
\text { items }\end{array}$ & Adapted from \\
\hline Extraversion & $\begin{array}{l}\text { General tendency to experience } \\
\text { positive emotions and be sociable, } \\
\text { active and lively (Noguchi, Gohm, } \\
\text { \& Dalsky, 2006) }\end{array}$ & Hahn et al. (2012) \\
& $\begin{array}{l}\text { Propensity to experience negative } \\
\text { traits such as anxiousness, stress } \\
\text { and depression (Noguchi et al., }\end{array}$ & \\
2006) & & \\
Introversion & $\begin{array}{l}\text { Level of uncertainty that the } \\
\text { investor is capable of tolerating in } \\
\text { order to achieve greater incentives } \\
\text { (Dhiman \& Raheja, 2018; Mishra, }\end{array}$ & 5 & \\
2018) & & \\
Risk Tolerance & $\begin{array}{l}\text { Perceived performance of } \\
\text { investments (Sadiq \& Amna, 2019) } \\
\text { Experience of investor for } \\
\text { investing on stock market in years } \\
\text { (Awais et al., 2016) }\end{array}$ & Weber et al. (2002) \\
Investment & & Wood and \\
Decisions & & Zaichkowsky (2004) \\
Investment & & & \\
Experience & & & \\
\hline
\end{tabular}

\section{Estimation Method}

SEM (Structural Equation Modeling) is used to make analysis of structural relationships among variables. This multivariate statistical technique is the combination of multiple regression analysis and confirmatory factor analysis. PLSSEM (Statistical software) seemed to be very efficient for complete assessment of the theoretical model. Most often, PLS-SEM results are presented into two phases: goodness of measures and testing theoretical model.

\section{Results and discussion}

\section{Goodness of Measure}

The first phase of PLS-SEM involves measuring the goodness of the model (i.e., Reliability and validity). Motive behind these checks is to test whether the construct is true representative of interest variables, otherwise such measures should not be used for the assessment of theoretical model.

Table 2.

Reliability Analysis

\begin{tabular}{lll}
\hline Variables & Cronbach's Alpha & Composite Reliability \\
\hline Extroversion & 0.701 & 0.781 \\
Introversion & 0.815 & 0.701 \\
Investment Decision & 0.768 & 0.852 \\
Risk Tolerance & 0.789 & 0.762 \\
\hline
\end{tabular}

Cronbach's alpha represents the reliability of the instrument. The value of Cronbach's alpha ranges between 0 to 1 and its threshold value is 0.7 (Kline, 2005). In Table 2, each variable has value of Cronbach's alpha above 0.70 which confirms the internal consistency of the instrument. Based upon the results reported on composite reliability, all variables are proved to have high level of internal consistency as compared to the threshold i.e. 0.70 (Hair, Hult, Ringle, \& Sarstedt, 2014). 


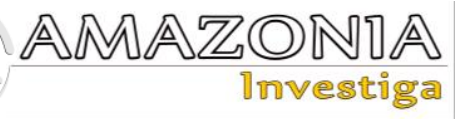

Table 3.

Discriminant Validity (HTMT) Analysis.

\begin{tabular}{lllll}
\hline & Extroversion & Introversion & Investment Decision & Risk Tolerance \\
\hline Extroversion & & & & \\
Introversion & 0.796 & & & \\
investment decision & 0.635 & 0.377 & & \\
risk tolerance & 0.690 & 0.542 & 0.463 & \\
\hline
\end{tabular}

Discriminant validity of the measurement model is done through Hetrotrait-Monotrait (HTMT) Ratio. Based upon the results presented in Table 3 , all constructs have values that are lesser than the threshold of 0.90 (Hair, Hult, Ringle, \& Sarstedt, 2017). Thus the findings confirm that each construct is empirically different from other constructs.

Table 4.

Convergent Validity (Average variance Extracted)

\begin{tabular}{ll}
\hline Variables & AVE \\
\hline Extroversion & 0.426 \\
Introversion & 0.434 \\
Investment Decision & 0.593 \\
Risk Tolerance & 0.536 \\
\hline
\end{tabular}

Convergent Validity can be estimated by AVE. Based upon the results reported in Table 4, the values of AVE for investment decisions and risk tolerance are greater than 0.5 which is threshold value (Chin, Peterson, \& Brown, 2008). Personal characteristics-extroversion and introversion are seemed to be weak in terms of convergent validity as the values of AVE are less than 0.5 (Chin, Peterson, \& Brown, 2008). According to Ali and Mehta (2020), the value of AVE lesser than 0.50 but more than 0.40 is acceptable.

Model Evaluation

Table 5.

Predictive and Relevance Accuracy.

\begin{tabular}{lcccc}
\hline & R Square & R Square Adjusted & Q2 & Effect Size \\
\hline Investment Decision & 0.302 & 0.287 & 0.164 & Medium \\
Risk Tolerance & 0.262 & 0.237 & 0.075 & Small \\
\hline
\end{tabular}

Effect Size: Small: 0.0 < Q2 effect size < 0.15; Medium: 0.15 < Q2 effect size < 0.35; Large: Q2 effect size $>0.35$ (Ali, Farooq, \& Naqvi, 2020)

Value of adjusted $\mathrm{R}$ Square represents the explanatory power of the model. The value of adjusted $\mathrm{R}$ Square must be in between 0 and 1 . The value of adjusted $\mathrm{R}$ Square closer to 1 indicate better predictive power of the model.
Moreover, the predictive relevance of the model in PLS-SEM is estimated by Stone-Geisser Q2 (Ali et al., 2020). In this paper, the effect size of Q2 varies from small to medium.

Table 6.

Description of Model Fit.

\begin{tabular}{lc}
\hline & Estimated Model \\
\hline Standardized Root Mean Square (SRMR) & 0.070 \\
Chi-Square & 1016.681 \\
NFI & 0.768 \\
\hline
\end{tabular}


The value of Standardized Root Mean Square (SRMR) should be less than 0.08 for the fitness of the estimated model (Ali \& Qazi, 2018). In estimated model SRMR value is 0.070 which confirms the fitness of this model.

\section{PLS Path Model Analysis (Bootstrapping)}

In order to add more precision to our results, the procedure of bootstrapping is used.
Bootstrapping is basically the nonparametric technique which helps in more precise estimation (Ali \& Qazi, 2019). In this program, Path coefficients for inner model are generated for testing the significance. Moreover, the results extracted using bootstrapping highlight the significance of path coefficients. Figure 2 represents the structural model estimated through procedure of bootstrapping.

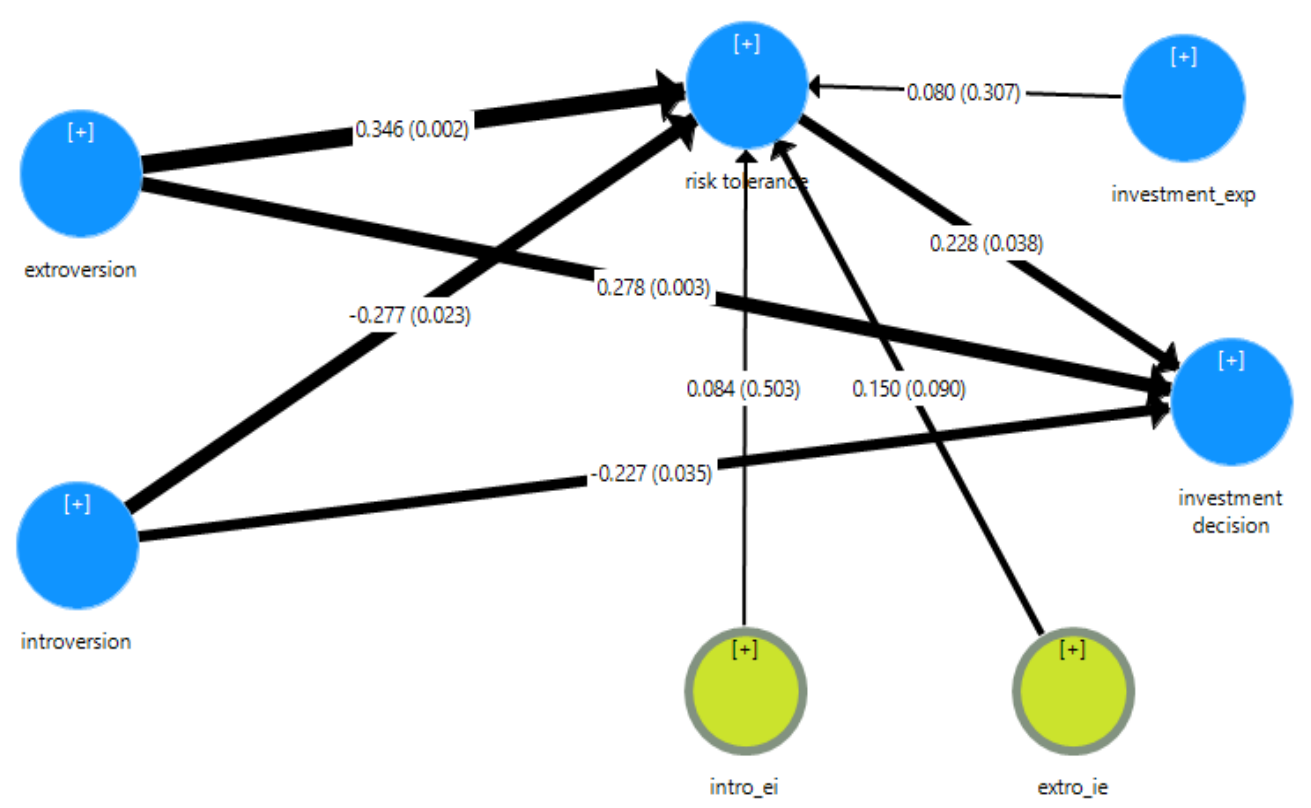

Figure 2. Path Analysis.

Figure 2 represents the structural model for this study. In this model, arrows represent the hypothesized relationships. Table 7 and Table 8 provide the coefficients summary with the level of significance. All path coefficients are supporting hypothesized relationships except the moderating effect of investment experience on the association between introversion and risk tolerance.

Table 7.

Direct Path Coefficients.

\begin{tabular}{llllll}
\hline & $\begin{array}{l}\text { Original } \\
\text { Sample }(\mathbf{O})\end{array}$ & $\begin{array}{l}\text { Sample } \\
\text { Mean }(\mathbf{M})\end{array}$ & $\begin{array}{l}\text { Std. Deviation } \\
(\text { STDEV) }\end{array}$ & $\begin{array}{l}\text { T Values } \\
(\mid \mathbf{O} / \mathbf{S T D E V})\end{array}$ & $\begin{array}{l}\text { Sig. (P } \\
\text { Values) }\end{array}$ \\
\hline $\begin{array}{l}\text { Extro_ie -> Risk Tolerance } \\
\text { Extroversion -> Investment }\end{array}$ & 0.150 & 0.148 & 0.088 & 1.698 & 0.090 \\
$\begin{array}{l}\text { Decision } \\
\text { Extroversion -> Risk }\end{array}$ & 0.278 & 0.283 & 0.092 & 3.026 & 0.003 \\
$\begin{array}{l}\text { Tolerance } \\
\text { Intro_ei -> Risk Tolerance }\end{array}$ & 0.346 & 0.329 & 0.112 & 3.075 & 0.002 \\
$\begin{array}{l}\text { Introversion -> Investment } \\
\begin{array}{l}\text { Decision } \\
\text { Introversion -> Risk }\end{array}\end{array}$ & -0.227 & 0.083 & 0.126 & 0.670 & 0.503 \\
$\begin{array}{l}\text { Tolerance } \\
\begin{array}{l}\text { Investment_Exp -> Risk } \\
\text { Tolerance }\end{array}\end{array}$ & -0.277 & -0.237 & 0.108 & 2.109 & 0.035 \\
$\begin{array}{l}\text { Risk Tolerance -> } \\
\text { Investment Decision }\end{array}$ & 0.080 & 0.0704 & 0.122 & 2.275 & 0.023 \\
\hline
\end{tabular}


Table 8.

Indirect Path Coefficients.

\begin{tabular}{|c|c|c|c|c|c|}
\hline Indirect Path Coefficients & $\begin{array}{l}\text { Original } \\
\text { Sample } \\
\text { (O) }\end{array}$ & $\begin{array}{l}\text { Sample } \\
\text { Mean } \\
(\mathrm{M})\end{array}$ & $\begin{array}{l}\text { Std. } \\
\text { Deviatio } \\
\text { n } \\
\text { (STDEV) }\end{array}$ & $\begin{array}{l}\text { T Values } \\
\text { (|O/STDEV| } \\
\text { ) }\end{array}$ & $\begin{array}{l}\text { Sig. (P } \\
\text { Values) }\end{array}$ \\
\hline $\begin{array}{l}\text { Extro_ie -> Risk Tolerance -> } \\
\text { Investment Decision }\end{array}$ & 0.034 & 0.032 & 0.024 & 1.412 & 0.058 \\
\hline $\begin{array}{l}\text { Extroversion -> Risk Tolerance -> } \\
\text { Investment Decision }\end{array}$ & 0.079 & 0.075 & 0.046 & 1.712 & 0.087 \\
\hline $\begin{array}{l}\text { Intro_ei -> Risk Tolerance -> } \\
\text { Investment Decision }\end{array}$ & 0.019 & 0.016 & 0.031 & 0.621 & 0.535 \\
\hline $\begin{array}{l}\text { Introversion -> Risk Tolerance -> } \\
\text { Investment Decision }\end{array}$ & -0.063 & -0.071 & 0.046 & 1.378 & 0.068 \\
\hline $\begin{array}{l}\text { Investment_Exp -> Risk Tolerance -> } \\
\text { Investment Decision }\end{array}$ & 0.018 & 0.019 & 0.023 & 0.789 & 0.430 \\
\hline
\end{tabular}

Summary statistics of indirect path coefficients is given in Table 8 . All indirect path coefficients are significant (P Value $<0.1$ ) except the moderating role of investment experience in relationship between introversion and risk tolerance.

The findings of our study reveals that extraversion has significant positive impact on investment decisions (tested by direct path coefficients); thus $H_{\circ_{1}}$ is rejected and results are in agreement with extant literature (e.g. Sadiq \& Amna, 2019). Introversion has significant positive impact on investment decisions, as proven by direct path coefficients. Hence, we reject $\mathrm{H}_{\circ_{2}}$ and this finding is supported by existing literature (e.g.Oehler et al., 2018; Sadiq \& Amna, 2019). In additions to these direct impacts, risk tolerance significantly mediate the association between extraversion and investment choices (through indirect path coefficients) and the findings are consistent with literature (e.g. Czerwonka, 2019; Gambetti \& Giusberti, 2019). Thus, $\underline{H_{0 z}}$ is rejected. Similarly, risk tolerance also significantly mediates the relationship between introversion and investment decisions. Therefore, $H_{{ }^{\circ}}$ is rejected and results are in accordance with extant literature (Dhiman \& Raheja, 2018; Pinjisakikool, 2018).

Investment experience plays conditional role in the association between extraversion and investors' risk tolerance that reject $H_{{ }^{\circ}}$. In contrast, moderating role of investment experience has found to be insignificant. Thus, fail to reject $H_{{ }^{\circ}}$. Due to scarce literature, could not find any empirical evidence to validate these findings which calls for the need to further explore this relationship the moderating role of investment experience in the relationship between personality traits and investment decisions by potential researchers.

\section{Conclusions and Implications}

Investment decisions, that were traditionally considered to be rational, are proved to be manipulated by behavioral biases. In this paper, extraversion and introversion are studied as personality traits. This paper has investigated the intervening role of risk tolerance in the relationship between personality traits and investment decisions. Furthermore, the study gauged the conditional role of investment experience in the relationship between personality traits and risk tolerance. Thus mediated-moderation model has been employed for testing the structural relationships. The data has been collected from 175 individual investors of Pakistan Stock Exchange using convenient sampling technique.

This empirical paper confirms that extraverted investors are more open to greater risk. Hence, high level of risk tolerance leads to the success of investment decisions. Because higher risks come up with higher return (Rogers et al., 2013). On the other hand, introverted investors are reserved and take comparatively rational decisions. Consequently, they exhibit low level of risk tolerance, which negatively affect their investment decisions (Lin, 2018). Moreover, investment experience moderates the association of personality traits and investors' risk tolerance. Greater the investment experience, greater will the risk tolerance in individual investors. To sum up the discussion, investment experience positively moderates the relationship between extroversion and investment decisions through risk tolerance. this implies that investors who are extrovert, having investment experience are high risk takers than introvert investors. Thus, extroversion personality trait helps in making timely and efficient investment decisions. 
However, investment experience does not moderate the nexus between extroversion and investment decisions through risk tolerance which implies that individual having introvert personality does not take timely and efficient investment decisions despite having investment experience.

These findings of this study are expected to be helpful for investors to eliminate or minimize the behavioral biases in the investment decision process. Moreover, investors will be able to choose better investment alternatives, as this study can help them to recognize the judgmental error and biases faced by investors. The findings can also help financial advisors to provide quality advice to their clients by understanding their personal characteristics (Nguyen et al., 2019). Moreover, investment advisors should consider personal characteristics and individual risk tolerance, among other factors, when giving investment advice to private investors.

\section{Limitations and Future Directions}

Despite substantial contribution in literature, it is observed certain deficiencies in this study. First and foremost is the small sample size as we have faced difficulties in data collection due to COVID-19. Second limitation is that data was collected only form individual investors who have invested at Pakistan Stock Exchange. Thus, further research can also include institutional investors in sample. Likewise, this study can be replicated for investors on Pakistan Mercantile Exchange. Moreover, other personality traits, such as agreeableness, conscientiousness, neuroticism, can be studied along extraversion and introversion. Last but not the least; potential scholars can also gauge demographic differences in terms of risk tolerance and investment decisions.

\section{References}

Ahmad, M., Hassan, A., Mahmood, S., \& Aslam, S. (2016). Impact of investor personality types with interaction effects of demographics on investment behavior: Evidence from Pakistan. Pakistan Journal of Commerce and Social Sciences, 10(3), 638-658.

Aini, N. S., \& Lutfi, L. (2019). The influence of risk perception, risk tolerance, overconfidence, and loss aversion towards investment decision making. Journal of Economics, Business \& Accountancy Ventura, 21(3), 401-413. https://doi.org/10.14414/jebav.v21i3.1663
Akhtar, F., Thyagaraj, K. S., \& Das, N. (2018). The impact of social influence on the relationship between personality traits and perceived investment performance of individual investors: Evidence from Indian stock market. International Journal of Managerial Finance, 14(1), 130-148. https://doi.org/10.1108/IJMF-05-2016-0102

Ali, F. H. \& Farooq, S., \& Naqvi, F. N. (2020). Can cognitive crafting enhance business performance? The mediating role of employee ambidexterity in the context of small and medium enterprises. International Journal of Management Research and Emerging Sciences, 10(2), 85-95.

Ali, F. H. \& Mehta, A. M. (2020). Is smartphone loafing energizing, creative, innovative and productive at the workplace? Academy of Marketing Studies Journal, 24(3), 1-13.

Ali, F. H. \& Qazi, A. A. (2018). The role of creative self-efficacy and intrinsic motivation in delighting customers: The mediating role of positive psychological capital. Pakistan Journal of Commerce and Social Sciences, 12(1), 78-93. Ali, F. H. \& Qazi, A. A. (2019). Can social media platforms enable co-creation as a tool in political marketing? The South Asian context. South Asian Studies, 34(1), 81-102.

Aren, S., \& Zengin, A. N. (2016). Influence of financial literacy and risk perception on choice of investment. Procedia. Social and Behavioral Sciences, 235, 656-663. https://doi.org/10.1016/j.sbspro.2016.11.047

Awais, M., Laber, M. F., Rasheed, N., \& Khursheed, A. (2016). Impact of financial literacy and investment experience on risk tolerance and investment decisions: Empirical evidence from Pakistan. International Journal of Economics and Financial Issues, 6 (1), 73-79.

Baruah, M., \& Parikh, A. K. (2018). Impact of risk tolerance and demographic factors on financial investment decision. GIS Business, 13(5),

31-40. https://doi.org/10.26643/gis.v13i5.3270

Chavali, K., \& Mohanraj, M. P. (2016). Impact of demographic variables and risk tolerance on investment decisions: An empirical analysis. International Journal of Economics and Financial Issues,6(1), 169-175.

Chin, W. W., Peterson, R. A., \& Brown, S. P. (2008). Structural equation modelling in marketing: Some practical reminders. Journal of Marketing Theory and Practice, 16(4), 287-298. Czerwonka, M. (2019). Cultural, cognitive and personality traits in risk-taking behaviour: Evidence from Poland and the United States of America. Journal Economic Research, 32(1), 894-908. https://doi.org/10.1080/1331677X.2019.158876 6 


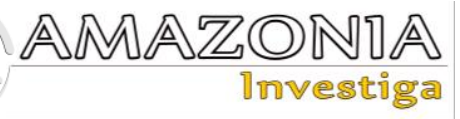

Dhiman, B., \& Raheja, S. (2018). Do personality traits and emotional intelligence of investors determine their risk tolerance? Management and Labour Studies, 43(1-2), 88-99. https://doi.org/10.1177/0258042X17745184 Dickason, Z., Ferreira, S., \& McMillan, D. (2018). Establishing a link between risk tolerance, investor personality and behavioural finance in South Africa. Cogent Economics \& Finance, $\quad 6(1), \quad 1519898$. https://doi.org/10.1080/23322039.2018.1519898 Eysenck, H. J. (1950). Dimensions of personality. London. United Kingdom; Transaction Publishers.

Eysenck, H. J. (1982). Personality, genetics, and behavior: Selected papers. New York, NY: Praeger.

Fama, E. (1970). Efficient capital markets: A review of theory and empirical work. The Journal of Finance, 25(2), 383-417. doi: $10.2307 / 2325486$

Gambetti, E., \& Giusberti, F. (2019). Personality, decision-making styles and investments. Journal of Behavioral and Experimental Economics, 80, 14-24.

https://doi.org/10.1016/j.socec.2019.03.002

Hahn, E., Gottschling, J., \& Spinath, F. M. (2012). Short measurements of personality Validity and reliability of the GSOEP Big Five Inventory (BFI-S). Journal of Research in Personality, 46(3), 355-359. https://doi.org/10.1016/j.jrp.2012.03.008

Hair, J. F., Hult, G. T. M., Ringle, C., \& Sarstedt, M. (2014). A primer on partial least squares structural equation modelling (PLS-SEM). Thousand Oaks, CA: Sage.

Hair, J. F., Hult, G. T. M., Ringle, C., \& Sarstedt, M. (2017). A primer on partial least squares structural equation modelling (PLS-SEM) (2nd ed.). Thousand Oakes, CA: Sage.

Ibbotson, R. G., Idzorek, T. M., Kaplan, P. D., \& Xiong, J. X. (2018). Popularity: Bridge between classical and behavioral finance. CFA Institute Research Foundation.

Kahneman, D., \& Tversky, A. (1979). Prospect theory: An analysis of decision under risk. Econometrica, 47(2), 263-291. https://doi.org/10.2307/1914185

Kanagasabai, B., \& Aggarwal, V. (2020). The mediating role of risk tolerance in the relationship between financial literacy and investment performance. Colombo Business Journal, 11(1), 83-104. https://doi.org/10.4038/cbj.v11i1.58

Kline, R.B. (2005), Methodology in the social sciences. NY: New York: SAGE.

Kourtidis, D., Šević, Z., \& Chatzoglou, P. (2011). Investors' trading activity: A behavioural perspective and empirical results. The Journal of
Socio-Economics, $\quad 40(5), \quad 548-557$. https://doi.org/10.1016/j.socec.2011.04.008.

Kubilay, B., \& Bayrakdaroglu, A. (2016). An empirical research on investor biases in financial decision-making, financial risk tolerance and financial personality. International Journal of Financial Research, 7(2), p.171. https://doi.org/10.5430/ijfr.v7n2p171

Liaqat, F., Mahmood, K., \& Ali, F. H. (2020). Demographic and socio-economic differences in financial information literacy among university students. Information Development, 1-13. Advance online publication.

Lin, Z. (2018). Psychological Factors behind Risk-Taking Behaviors: Correlational Relations between Personality Traits and Financial Risk Tolerance (Master's Thesis). NYU Shanghai. https://shanghai.nyu.edu/sites/default/files/lin_zi xuan_thesis_nyush_honors_2018.pdf

Lippi, A., \& Rossi, S. (2020). Run for the hills: Italian investors' risk appetite before and during the financial crisis. International Journal of Bank Marketing, 38(5), 1195-1213.

Markowitz, H. M. (1952). Portfolio Selection. The Journal of Finance, 7, 77 - 91

Mehtab, F. (2019). MBTI personality types and risk perception of investors in India. Seshadripuram Journal of Social Sciences, 2(1), 30-43.

Mishra, R. (2018). Financial literacy, risk tolerance and stock market participation. Asian Economic and Financial Review, 8(12), 14571471.

https://doi.org/10.18488/journal.aefr.2018.812.1 457.1471

Noguchi, K., Gohm, C. L., \& Dalsky, D. J. (2006). Cognitive tendencies of focusing on positive and negative information. Journal of Research in Personality, 40(6), 891-910.

Nguyen, L., Gallery, G., \& Newton, C. (2019). The joint influence of financial risk perception and risk tolerance on individual investment decision-making. Accounting \& Finance, 59(S1), 747-771.

https://doi.org/10.1111/acfi.12295

Oehler, A., Wendt, S., Wedlich, F., \& Horn, M. (2018). Investors' personality influences investment decisions: Experimental evidence on extraversion and neuroticism. Journal of Behavioral Finance, 19(1), 30-48. https://doi.org/10.1080/15427560.2017.1366495 Pak, O. \& Mahmood, M. (2015). Impact of personality on risk tolerance and investment decisions. International Journal of Commerce and Management, 25(4), 370-384.

Perugini, M., \& De Raad, B. (2001). Editorial: Personality and economic behaviour. European Journal of Personality, 15(S1), S1-S4. https://doi.org/10.1002/per.427 
Pinjisakikool, T. (2018). The influence of personality traits on households' financial risk tolerance and financial behaviour. Journal of Interdisciplinary Economics, 30(1), 32-54. https://doi.org/10.1177/0260107917731034

Powell, M., \& Ansic, D. (1997). Gender differences in risk behaviour in financial decision-making: An experimental analysis. Journal of Economic Psychology, 18(6), 605628.

Radin, M. (1932). The endless problem of corporate personality. Columbia Law Review, 32(4), 643-667.

Revelle, W. (2016). Hans Eysenck: Personality theorist. Personality and Individual Differences, 103 , 32-39.

https://doi.org/10.1016/j.paid.2016.04.00

Ricciardi, V., \& Simon, H. K. (2000). What is behavioral finance? Business. Education \& Technology Journal, 2(2), 1-9.

Robinson, D. L. (1986). A commentary on Gray's critique of Eysenck's theory. Personality and Individual Differences, 7(4), 461-468. https://doi.org/10.1016/0191-8869(86)90124-8 Rogers, J., Viding, E., \& Chamorro-Premuzic, T. (2013). Instrumental and disinhibited financial risk taking: Personality and behavioural correlates. Personality and Individual Differences, 55(6), 645-649. https://doi.org/10.1016/j.paid.2013.05.011

Sadiq, M., \& Amna, H. (2019). Impact of personality traits on risk tolerance and investors' decision making. International Journal of Applied Behavioral Economics, 8(1), 1-20. https://doi.org/10.4018/IJABE.201901010

Salman, M., Khan, B., \& Javed, A. (2020). Moderated mediation: The impact of heuristic representativeness bias on investment decisionmaking. Academic Journal of Social Sciences, 4(2), 354-363.

Weber, E. U., Blais, A.-R., \& Betz, N. E. (2002). A domain-specific risk-attitude scale: Measuring risk perceptions and risk behaviors. Journal of Behavioral Decision Making, 15(4), 263-290. https://doi.org/10.1002/bdm.414

Wood, R., \& Zaichkowsky, J. L. (2004). Attitudes and Trading Behavior of Stock Market Investors: A Segmentation Approach. Journal of Behavioral Finance, 5(3), 170-179. https://doi.org/10.1207/s15427579jpfm0503_5 Yao, R., Sharpe, D. L., \& Wang, F. (2011). Decomposing the age effect on risk tolerance. The Journal of Socio-Economics, 40(6), 879887. https://doi.org/10.1016/j.socec.2011.08.023 